\title{
The impact of peppermint oil on the irritable bowel syndrome: a meta-analysis of the pooled clinical data
}

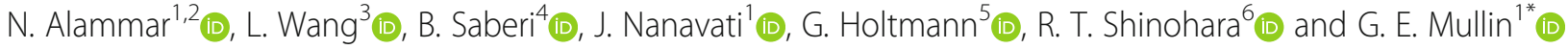

\begin{abstract}
Background: Peppermint oil (PO) has intrinsic properties that may benefit patients with irritable bowel syndrome (IBS) symptoms. The study objective was to determine the effect of peppermint oil in the treatment of the IBS.

Methods: We systematically searched MEDLINE (PubMed), Cochrane Central Register of Controlled Trials (Cochrane CENTRAL), ClinicalTrials.gov, EMBASE (Ovid), and Web of Science for randomized controlled trials (RCTs) of PO for IBS. We appraised the eligible studies by the Cochrane risk of bias tool. We performed random-effects meta-analysis on primary outcomes including global improvement in IBS symptoms and abdominal pain. A PRISMA-compliant study protocol is registered in PROSPERO Register [2016, CRD42016050917].

Results: Twelve randomized trials with 835 patients were included. For global symptom improvement, the risk ratio (RR) from seven RCTs for the effect of PO $(n=253)$ versus placebo $(n=254)$ on global symptoms was 2.39 [95\% confidence interval $(\mathrm{Cl}): 1.93,2.97], P=0 \%, z=7.93(p<0.00001)$. Regarding abdominal pain, the RR from six RCTs for the effect of PO $(n=278)$ versus placebo $(n=278)$ was $1.78[95 \% \mathrm{Cl}: 1.43,2.20], P^{2}=0 \%, z=5.23(p<0.00001)$. Overall, there were no differences in the reported adverse effects: PO (32 events, 344 total, 9.3\%) versus placebo (20 events, 327 total, 6.1\%) for eight RCTs; RR 1.40 [95\% Cl: 0.87, 2.26] $\left.\right|^{2}=0 \%, z=1.39(p=0.16)$. The number needed to treat with $\mathrm{PO}$ to prevent one patient from having persistent symptoms was three for global symptoms and four for abdominal pain.
\end{abstract}

Conclusions: In the most comprehensive meta-analysis to date, PO was shown to be a safe and effective therapy for pain and global symptoms in adults with IBS.

Keywords: Irritable bowel syndrome, IBS, Peppermint oil, Global symptom relief, Abdominal pain, Meta-analysis, PRISMA

\section{Background}

The irritable bowel syndrome (IBS) is a chronic, functional gastrointestinal syndrome characterized by relapsing abdominal pain and altered bowel habits, with either predominant symptoms of diarrhea (IBS-D), constipation (IBS-C), both (IBS-M), or undetermined (IBS-U), and is categorized according to the Rome IV criteria [1]. As a common digestive tract disorder, IBS affects an estimated $5-15 \%$ of Western populations [2]. Lovell and Ford conducted a meta-analysis of the world's literature

\footnotetext{
* Correspondence: gmullin1@jhmi.edu

${ }^{1}$ The Division of Gastroenterology and Hepatology, The Johns Hopkins

University School of Medicine, 600 N. Wolfe Street, Baltimore, MD 21287, USA Full list of author information is available at the end of the article
}

and reported that, on a global scale, IBS is seen predominantly in females, and the age of onset is typically under 50 years-of-age [3]. In their research, Lovell and Ford found the global prevalence of IBS to be $11.2 \%$ (95\% confidence interval [CI], 9.8-12.8\%) [3]. IBS accounts for a significant number of annual visits to primary care physicians, health-care utilization, quality of life, and adverse economics owing to absenteeism from work [4].

The pathophysiology of IBS is complex and involves an interaction of various factors, which includes, but is not limited to, genetic predisposition, gut-brain axis, visceral sensitivity, gastrointestinal motility, gut dysbiosis, neurotransmitters, food reactions, intestinal permeability, bile acids, inflammatory mediators, early-life 
stressors, psychosocial maladaptation, and somatization, among others [5]. IBS patients with mild and intermittent symptoms usually benefit from lifestyle and dietary modification, which includes a diet low in fermentable oligo-, di-, and monosaccharides and polyols (FODMAPs) [6]; and in some cases, lactose and gluten avoidance [7]. Smooth muscle relaxants and antispasmodics can also be used to help with IBS symptoms, especially abdominal pain and bloating [8].

Peppermint oil (PO) (Mentha Piperita) is a naturally-occurring carminative herb containing monoterpene compounds that target the pathophysiology of IBS. PO contains L-menthol, which blocks calcium channels in smooth muscle, thus producing antispasmodic effects on the gastrointestinal tract [9]. PO possesses antimicrobial, anti-inflammatory, antioxidant, immunomodulating, and anesthetic activities, all of which may be relevant for the treatment of IBS [10-12]. Several case reports, observational studies, and randomized clinical trials (RCTs) with methodological inconsistencies and heterogeneous outcomes have been reported since the research conducted by Rees et al. in 1979 [8, 13-20]. Earlier systematic reviews of RCTs of PO for IBS treatment revealed trial design flaws (e.g., no washout period for crossover trials), short follow-up duration, and conflicting trial results $[14,21]$. Some more recent systematic reviews of RCTs of PO for IBS treatment were limited in the lack of evidence for adverse events $[8,18]$. In addition, the risk-benefit profile of PO has been evolving as new RCTs continue to arise.

In 2016, Cash et al. reported the findings of a 4-week double blinded, placebo controlled RCT which tested a novel, proprietary, enteric-coated peppermint formulation $\left(\right.$ IBgard $\left.^{\circ}\right)$ for its potential efficacy in reducing IBS symptoms in 72 patients with IBS-M or IBS-D [22]. The specialized enteric-coating utilized in their trial consisted of a solid-state matrix that was triple-coated and designed to deliver PO with sustained release to the small intestine with fewer potential adverse effects. After $24 \mathrm{~h}$. of treatment, there was a reduction in the total IBS symptom score over baseline (mean change $-0.55, \mathrm{SD} \pm$ $0.613)$ vs. placebo (mean change $-0.27, \mathrm{SD} \pm 0.342)(p=$ 0.0092 ). At trial completion, there was a $40 \%$ reduction in the total IBS symptom score in the PO group compared to baseline (mean change $-1.16, \mathrm{SD} \pm 0.807$ ) vs. $24.3 \%$ (mean change $-0.70, \mathrm{SD} \pm 0.737$ ) with placebo $(P$ $=0.0246$ ). There was an increased improvement in both multiple and individual gastrointestinal symptoms, as well as in severe or unbearable symptoms compared to the placebo.

Given the recent findings by Cash et al. [22] and the potential limitations of previous meta-analyses, we conducted a systematic review and meta-analysis of available RCTs to determine the effect of peppermint oil in reducing the abdominal pain and global symptoms of irritable bowel syndrome and to evaluate the possible side effects of PO as compared to the placebo.

\section{Methods \\ Identification and retrieval of primary studies}

We conducted this systematic review and meta-analysis as per the PRISMA guidelines (i.e., the preferred reporting items of systematic reviews and meta-analysis) [23]. An experienced medical informationist (JN) developed and executed the research strategy in collaboration with the co-authors. There were no restrictions placed on publication dates. A preliminary search was executed on October 10, 2016, and repeated on October 10, 2017, and April 11, 2018, using the following databases: MEDLINE (PubMed), Cochrane Central Register of Controlled Trials (Cochrane CENTRAL), ClinicalTrials.gov, EMBASE (Ovid), and Web of Science. Controlled vocabulary terms for each concept were identified and combined with keyword synonyms. Web of Science was searched using keyword terms only (please see Additional file 1. Medical Literature Search Results for full search strategies). All results were downloaded to Endnote X8 (Thompson and Reuters, Philadelphia, Pennsylvania) and duplicate citations were identified and removed. The protocol is registered in PROSPERO Register [2016:CRD42016050917; (http://www.crd.york. ac.uk/PROSPERO/display_record.asp?ID=CRD42016050917)].

\section{Study selection and data extractions}

The titles and abstracts of the studies were carefully reviewed by two of the authors (GM, NA) independently to include RCTs that evaluated the influence of enteric-coated PO on IBS, based on the inclusion and exclusion criteria (Table 1). When there was a disagreement, a third reviewer (BS) determined whether the study qualified for inclusion. We also reviewed the bibliography of prior meta-analyses, review articles, and studies that underwent full-text screening for additional studies (reverse snowballing) to maximize the yield [24].

Once the articles met the criteria, the full text was reviewed and data extraction performed by four independent reviewers (GM, BS, GH, LW) based on data quality, sufficiency, and relevance. Disagreements were resolved by a third reviewer to reach a consensus. Our primary outcomes are proportion of patients with improvement in global symptoms and proportion of patients with improvement in abdominal pain. Extracted data included last name of the first author, year of publication, country of origin, study setting, demographic information of patients, publication year, population, sample size, study design, subtype(s) of IBS (if specified), criterion used for the IBS diagnosis, peppermint oil dose, preparation of peppermint oil, and patients enrolled and 
Table 1 Selection criteria for inclusion and exclusion

\begin{tabular}{ll}
\hline Criteria \\
\hline Inclusion & 1. Randomized placebo-controlled trials comparing pepper- \\
mint oil and placebo for irritable bowel syndrome with a \\
minimum treatment duration of 2 weeks. \\
2. Adult patients with irritable bowel syndrome as diagnosed \\
using any of the following criteria for IBS: Manning, Rome I, II, \\
III, IV diagnostic criteria. \\
Exclusion \\
1. Non-randomized trials; observational studies such as cohort \\
study, cross-sectional study, etc.. \\
2. Patients having organic disease or or did not have organic \\
disease excluded. \\
3. Treatment duration of less than 2 weeks. \\
4. Studies with inadequate data.
\end{tabular}

completed, and quantitative results. For RCTs with cross-over design, we only extracted data from the first stage before the wash-out period to account for intra-patient correlation of outcomes.

\section{Risk of bias, quality assessment, and data synthesis}

We used the modified Cochrane Collaboration's risk of bias assessment tool for RCTs. Bias was assessed as a judgment (high, low, or unclear) for individual elements from five domains (selection, performance, attrition, reporting, and other) [25]. Any disagreements were then discussed with a third reviewer (BS) with an agreement to be reached by consensus [25]. The Grading of Recommendations Assessment, Development, and Evaluation (GRADE) analysis was utilized to rate the evidence of our review, whereby very low $=1$, low $=2$, moderate $=3$, high $=4$. The strength of recommendations were 1 (strong) or 2 (weak) [26].

\section{Statistical analysis}

We pooled the results from included studies by random-effects meta-analysis with inverse variance weighting to determine the risk ratio (RR) and the 95\% confidence interval (95\% CI) for each outcome in RevMan 5.3.5 [27]. Q statistics, I-squared $\left(I^{2}\right)$, and tau-squared $\left(\tau^{2}\right)$ were calculated to assess statistical heterogeneity. For $Q$ statistics, a critical value of 0.1 was used to determine statistical significance. We considered an $I^{2}$ greater than 0.75 as a cutoff for considerable heterogeneity across studies. We planned to use funnel plots and Egger's test [28] to examine publication bias if the number of studies for an outcome is larger than ten. We conducted sensitivity analyses by removing studies with a high risk of bias per the Cochrane risk of bias tool.

\section{Results}

\section{Study selection}

A literature search conducted from inception to April 11, 2018, identified 759 studies. After duplicates were removed, a total of 427 studies remained for a review of titles and abstracts, from which 22 trials were identified that underwent full text screening. A total of ten studies were excluded (Additional file 2: Table of Excluded Studies), and twelve randomized studies (835 patients) that met the inclusion criteria were identified and underwent systematic review and data synthesis. A flow diagram of the study selection is summarized in Fig. 1.

\section{Study characteristics}

The included studies were published over five decades, from 1979 to 2016. Patients from Asia, Europe, and North America were recruited. Studies were of varied sample sizes, from 18 to 178 . The settings of most trials were teaching hospitals. Most studies were double-blind parallel group RCTs with follow-up durations ranging from 3 weeks to 12 weeks. Cross-over design were observed in three studies. Table 2 summarizes the characteristics of the included studies. Of note, among the twelve included studies, there was significant variation in the use of validated tools for the diagnosis of IBS. Alam et al. [29], Cappello et al. [30], Capanni et al. [31], and Merat et al. [32] utilized the Rome II criteria. Cash et al. [22] used the Rome III criteria and found a statistically significant benefit for PO relative to placebos for the global improvement of IBS symptoms. Dew et al. [33] conducted a double-blind cross-over study with a washout period defined by the recurrence of active symptoms, however, they failed to utilize any validated inclusion criteria. Lech et al. [34] failed to utilize any validated inclusion criteria, though they did find a significant benefit for PO relative to placebo for improvements in abdominal pain. Liu et al. [35] failed to utilize any validated inclusion criteria, though they did find a significant benefit for PO relative to placebo for the improvement of abdominal pain. Rees et al. [20], Schneider et al. [36], Weiss et al. [37], and Carling et al. [38] also failed to mention the use of validated inclusion criteria.

\section{Risk of bias assessment}

Incomplete outcome data was the most concerning problem observed in the included studies (Fig. 2). Six out of 12 studies were assessed as having high risk of attrition bias as these studies had over 10\% loss to follow-up and dealt with missing data by excluding those patients from final analyses. Two studies were funded by industry and were assessed as having high risk of bias due to conflicts of interest. In addition, random sequence generation and allocation concealment were not reported (unclear risk of selection bias) in many studies. In contrast, the blinding of participants and personnel were well performed in all studies (low risk of performance bias). The selective reporting was not observed in any studies (low risk of reporting bias). 


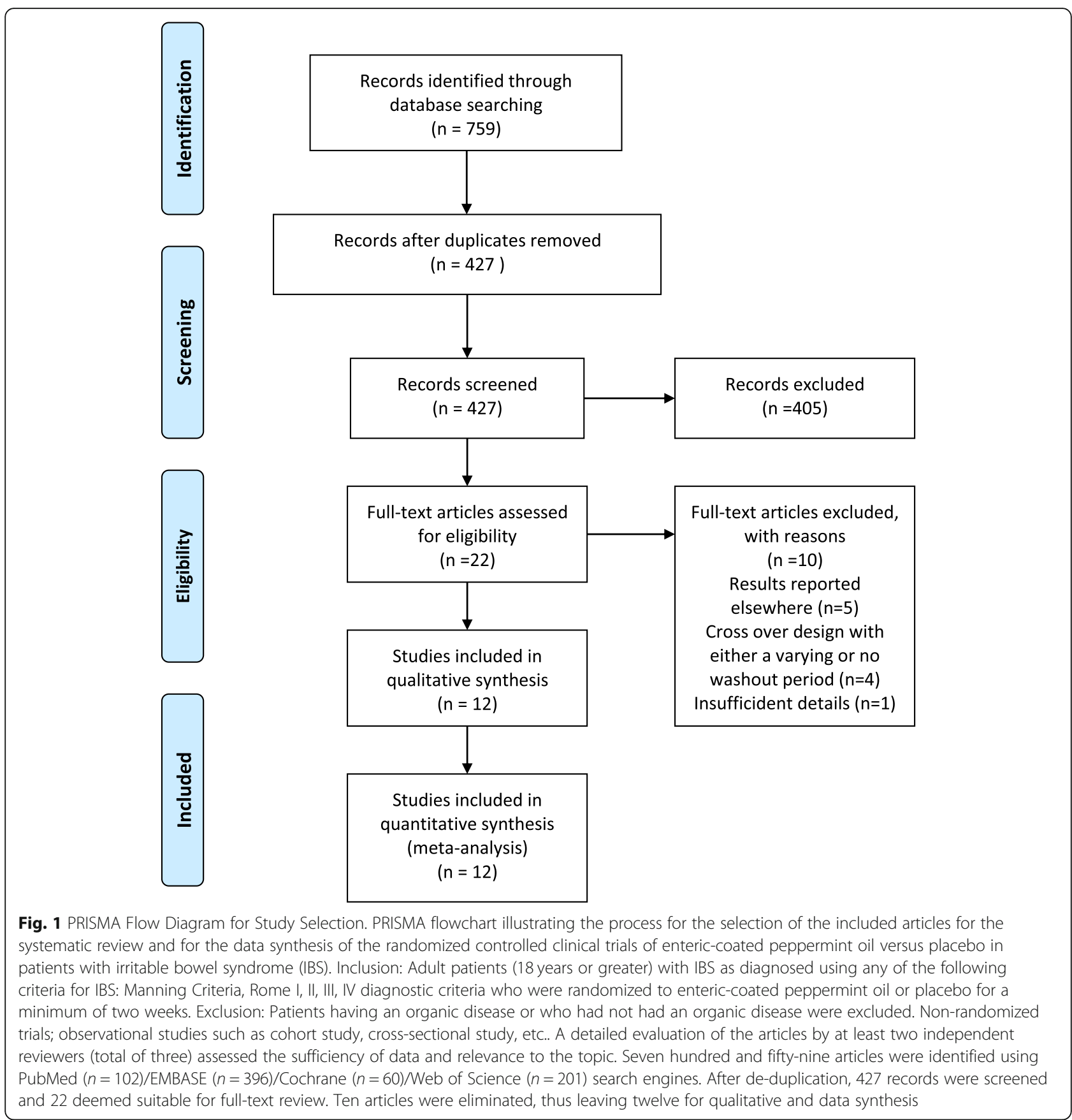

\section{Meta-analysis}

Seven studies reported treatment outcomes for the global improvement of IBS symptoms [20, 22, 31, 33-35, 37] (Fig. 3a). The risk ratio (RR) for seven RCTs for the effect of PO $(n=253)$ versus placebo $(n=254)$ on global symptoms was 2.39 [95\% confidence interval (CI): 1.93, 2.97], $I^{2}=0 \%, \mathrm{z}=7.93(p<0.00001)$ (Fig. 3a). The number of patients needed to be treated with peppermint oil versus the placebo to induce a global improvement of IBS symptoms was three (Table 3). No statistically significant heterogeneity was detected for this comparison $\left(\tau^{2}=0.00, X^{2}=5.29, P=0.51, I^{2}=0 \%\right.$ ) (Table 3 ).

Six studies reported treatment outcomes of improvement of abdominal pain [22, 31, 32, 34, 36] (Fig. 3b). The RR for six RCTs for the effect of PO $(n=278)$ versus placebo $(n=278)$ on abdominal pain was $1.78[95 \%$ CI: $1.43,2.20], I^{2}=0 \%, z=5.23$ ( $\mathrm{p}<0.00001$ ) (Fig. 2b). The number of patients that needed to be treated with peppermint oil versus the placebo to improve abdominal pain was four (Table 3). No statistically significant 
Table $\mathbf{2}$ Characteristics of Included Studies

\begin{tabular}{|c|c|c|c|c|c|c|c|}
\hline Year & Author & Country & Design & Setting & $\begin{array}{l}\mathrm{N} \\
\text { Enrolled }\end{array}$ & $\begin{array}{l}\mathrm{N} \\
\text { Completed }\end{array}$ & $\begin{array}{l}\text { Duration of } \\
\text { therapy }\end{array}$ \\
\hline 2013 & Alam & Bangladesh & Double-Blind RCT & $\begin{array}{l}\text { University Single- } \\
\text { Center }\end{array}$ & 74 & 65 & 6 weeks \\
\hline 2016 & Cash & USA & Double-Blind RCT & Multicenter & 72 & 70 & 4 weeks \\
\hline 2005 & Capanni & Italy & Double-Blind RCT & $\begin{array}{l}\text { University Single- } \\
\text { Center }\end{array}$ & 178 & 173 & 12 weeks \\
\hline 2007 & Cappello & Italy & Double-Blind RCT & $\begin{array}{l}\text { University Single- } \\
\text { Center }\end{array}$ & 57 & 50 & 4 weeks \\
\hline 1989 & Carling & Sweden & Double-blind Cross Over 3-arm RCT 1-Week Washout & $\begin{array}{l}2 \text { University } \\
\text { Centers }\end{array}$ & 40 & 38 & 2 weeks \\
\hline 1984 & Dew & Wales & Double-Blind Cross Over Washout Period & Multicenter & 29 & 29 & 2 weeks \\
\hline 1988 & Lech & Dutch & Double-Blind RCT & $\begin{array}{l}\text { University Single- } \\
\text { Center }\end{array}$ & 47 & 42 & 4 weeks \\
\hline 1997 & Liu & China & Double-Blind RCT & $\begin{array}{l}\text { University Single- } \\
\text { Center }\end{array}$ & 110 & 101 & 4 weeks \\
\hline 2009 & Merat & Iran & Double-blind RCT & $\begin{array}{l}\text { University Single- } \\
\text { Center }\end{array}$ & 90 & 60 & 8 weeks \\
\hline 1979 & Rees & UK & $\begin{array}{l}\text { Double-Blind Cross Over Washout Period Defined by } \\
\text { Recurrence of Active Symptoms }\end{array}$ & $\begin{array}{l}\text { University Single- } \\
\text { Center }\end{array}$ & 18 & 16 & 3 weeks \\
\hline 1990 & Schneider & USA & $\begin{array}{l}\text { Double-blind Cross Over RCT } \\
\text { 2-Week Washout }\end{array}$ & $\begin{array}{l}\text { University Single- } \\
\text { Center }\end{array}$ & 60 & 47 & 6 weeks \\
\hline 1988 & Weiss & Germany & Single blinded, RCT & $\begin{array}{l}\text { Hospital, single } \\
\text { center }\end{array}$ & 60 & 46 & 3 weeks \\
\hline
\end{tabular}

heterogeneity was detected for this comparison $\left(\tau^{2}=\right.$ $0.00, X^{2}=3.01, P=0.70, I^{2}=0 \%$ ) (Table 3).

Of the studies included, overall, only a few adverse events were reported. One study reported no adverse events [25]. Most of the reported adverse events were mild and transient. The adverse events included: heartburn [13, 15, 22, 23, 29, 30, 35], dry mouth [13, 23], belching [23], peppermint taste [15], rash [29], dizziness [23], headache [23], and less frequent increased appetite [23]. There was no statistically significant difference in reported adverse effects in IBS subjects using PO (32 events, 344 total, 9.3\%) versus placebo (20 events, 327 total, $6.1 \%$ ); RR 1.40 [95\% CI: $0.87,2.26$ ], $I^{2}=0 \%, \mathrm{z}=$ $1.39(p=0.16)$ (Fig. 3c).

The planned funnel plots and Egger's test for publication bias was not applicable as the number of studies for each outcome is less than ten because test power is usually too low to distinguish chance from real asymmetry [28, 39]. The sensitivity analyses excluding studies with high attrition bias provided similar results to our primary analyses.

The GRADE criteria were used to assess the overall quality of the evidence reported (Table 3) [26]. The global improvement in IBS symptoms outcomes was upgraded to high because of the large magnitude of the effect. The outcome of improvement of abdominal pain was downgraded to moderate because of the risk of bias. The outcome "adverse events" was downgraded to "low quality" because of the risk of bias and imprecision (Table 3).

\section{Discussion}

In this systematic review, we assessed the largest cohort of RCTs published over five decades involving twelve randomized clinical trials with 835 IBS patients from around the world. Overall, treatment with PO significantly improves abdominal pain and global symptoms of IBS. The available data are also consistent with a good safety profile. The strength of our findings is reflected by the large effect size of PO over placebo in the improvement of abdominal pain and global symptoms and by the low heterogeneity across included studies.

The first systematic review of RCTs of PO for the treatment of IBS was published by Pitter and Ernst in 1998, which included eight randomized trials involving 295 patients with seven of the eight trials not using the accepted clinical features of IBS [14]. The researchers performed a quantitative synthesis of five double-blind, placebo-controlled RCTs involving 265 participants [20, $33,34,38,40]$. Four of the five RCTs had a Jadad methodological quality score of three, with no RCTs scoring the maximum of five points [41]. Overall, the results demonstrated that $\mathrm{PO}$ was effective for the improvement of global symptoms in IBS $(p<0.001)$. However, two of the five studies showed no difference when using a placebo in IBS symptom improvement, and overall, there was a significant variation between the placebo responses across the five studies $(13-52 \%, p<0.01)$. No definitive conclusion could be drawn owing to the low 


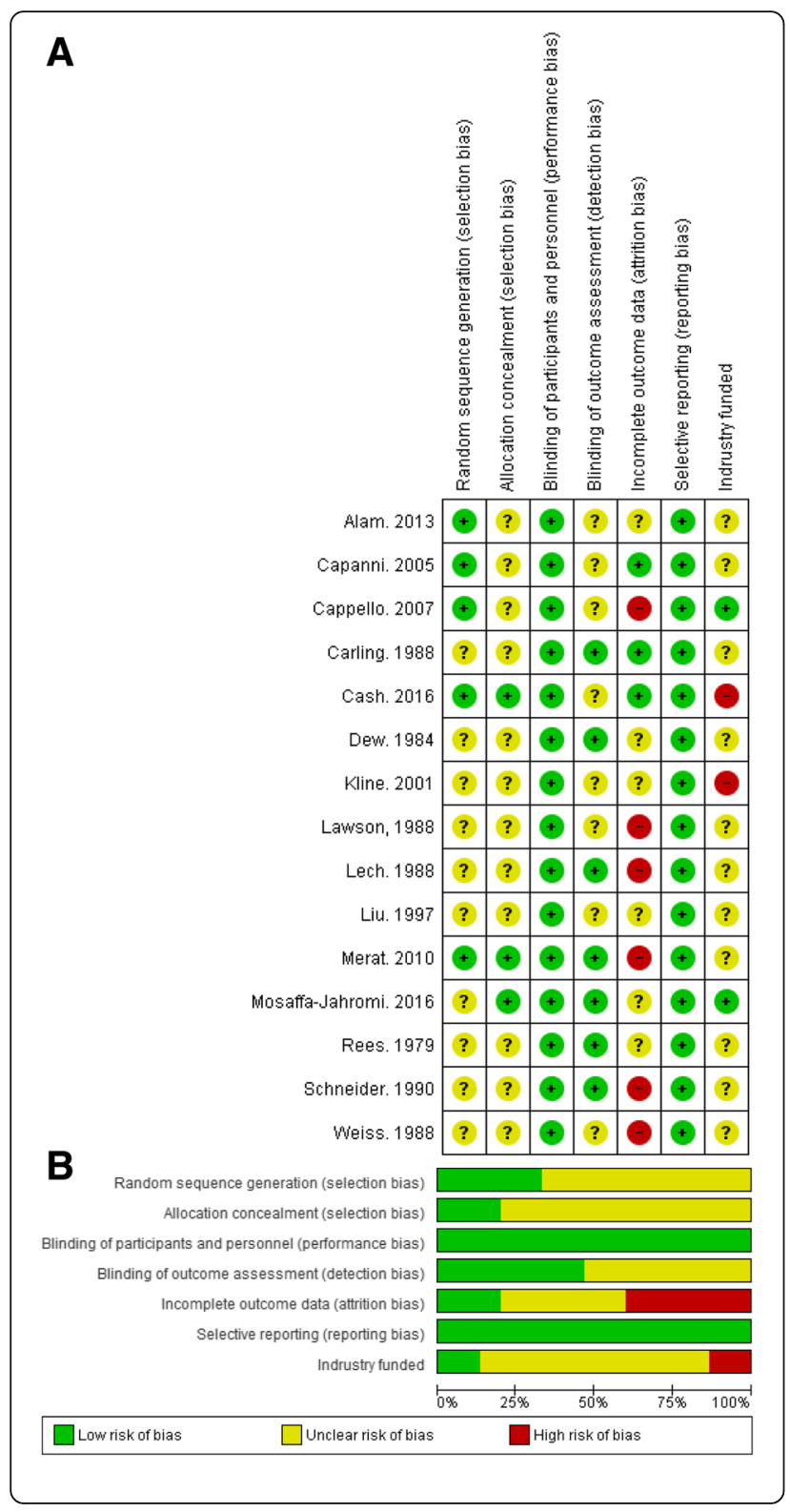

Fig. 2 a-b. Risk of Bias Assessment Using Cochrane the Collaboration's Tool. The included studies were evaluated for methodological flaws using the Cochrane Collaboration's risk of bias assessment tool. [25] a illustrates the risk of bias for each study. Studies were indexed by the last name of the first author and year of publication. Seven domains of risk of bias were assessed for each study, including random sequence generation, allocation concealment, blinding of participants and personnel, blinding of outcome assessment, incomplete outcome data, selective reporting,

and industry funded. +

denote low, unclear, and high risk of bias, respectively. Six of the 12 studies were assessed as having high risk of attrition bias and two studies were funded by industry (high risk of bias). Ten of the 12 included studies did not report random sequence generation and allocation concealment (unclear risk of selection bias). In contrast, the blinding of participants and personnel were well performed (low risk of performance bias in seven of the 12 included studies). Selective reporting was not observed in any studies (low risk if bias). Figure $2 \mathrm{~b}$ shows the overall risk of bias by domain: the risk of bias is displayed as low risk (green, +), unclear (yellow,?), or high risk (red, -)

quality of the primary studies, the overrepresentation of short-term $(<1$ month duration) studies, and the use of cross-over designs without washout periods in four of the five RCTs. The authors acknowledged that the results of their meta-analysis needed to be interpreted with caution due to the mentioned methodological flaws in the included studies. We also observed that six of the eight trials included in the Pittler and Ernst review [14] had treatment periods of one month or less. The studies included in this meta-analysis had treatment periods of two to twelve weeks, with seven studies being four weeks or greater, and found a significant benefit for PO relative to placebo for the improvement of abdominal pain and global IBS symptoms.

In 2004, Lesbros-Pantoflickova et al. performed a meta-analysis of the available pharmacological treatments for the irritable bowel syndrome, which included PO [21]. The authors included five studies [20,33, 34, 38, 40], with four having a Jadad score $\geq 3[33,38,40]$. Overall, the odds ratio (OR) of the five included studies favored $\mathrm{PO}$ for global symptoms over the placebo [OR 3.6, 95 CI\% 2.26.0]. Lesbros-Pantoflickova et al.s systematic review and meta-analysis lacked several methodological details and improperly concluded that Pittler's meta-analysis failed to demonstrate a beneficial effect for PO vs. placebo for improving IBS symptoms [14].

In 2008, Ford et al. reported the results of a qualitative and quantitative synthesis of the available studies for the effect of fiber, antispasmodics, and PO in the treatment of IBS [8]. Four of the included studies had a Jadad score $\geq 3[30,31,34,35]$ with a total of 392 participants to evaluate the effect of $\mathrm{PO}$ versus placebo on IBS symptoms. Ford et al. excluded the cross-over trials included by Pittler and Ernst [14]. They reported that the relative 


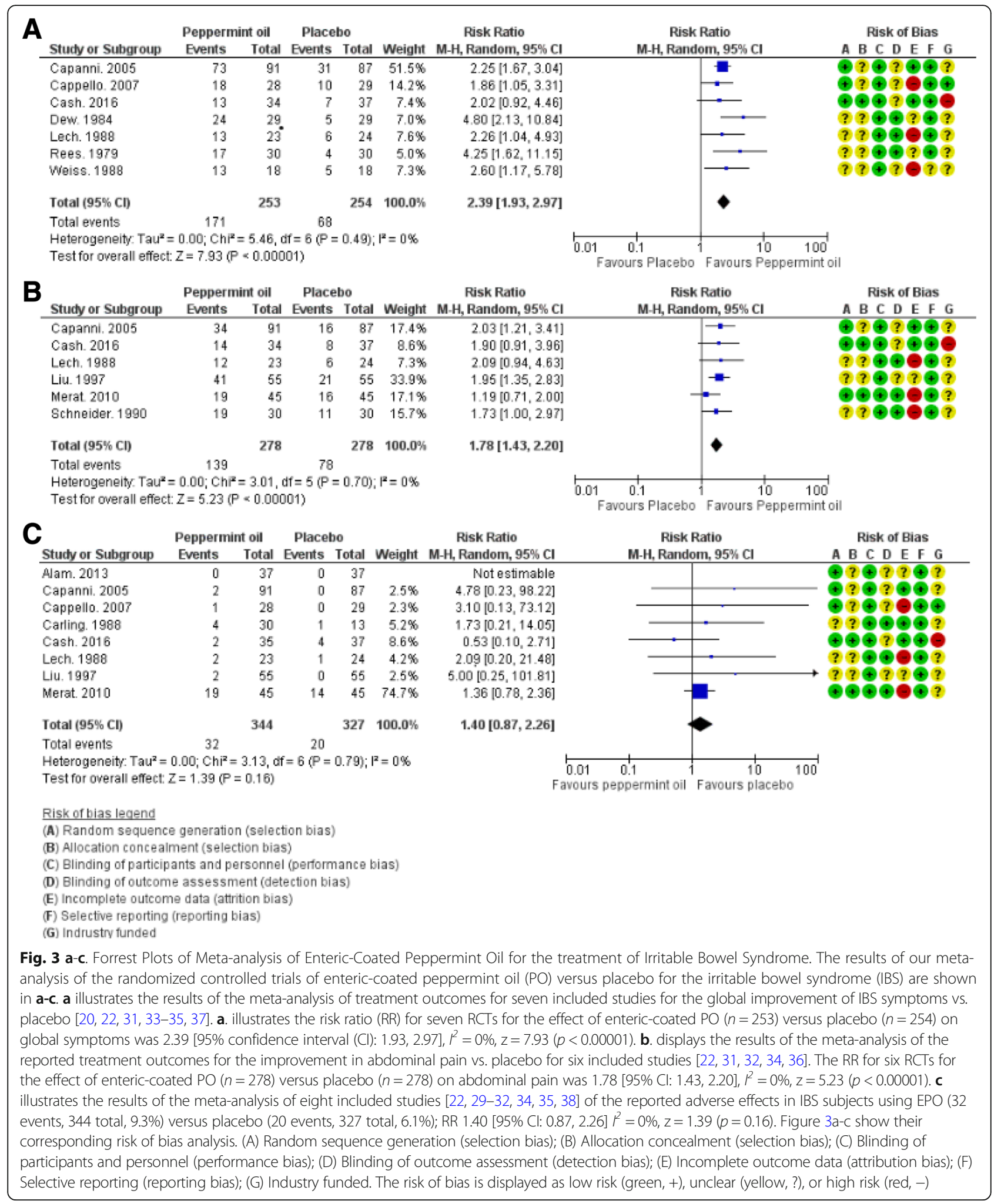

risk of persistent symptoms was 43\% less with PO (52/ 197 ; 26\%) when compared to placebo (127/195; 65\%) (relative risk, 0.43 ) without any significant heterogeneity between studies $\left(I^{2}=31.1 \%, P=0.23\right)$. The number needed to treat (NNT) with peppermint oil to prevent one patient from having persistent symptoms was 2.5 (2.0-3.0). The methodological details of the selection criteria and extraction were provided, however, the 
Table 3 Summary of Findings. Peppermint Oil vs. Placebo for the Treatment of IBS

\begin{tabular}{|c|c|c|c|c|c|c|}
\hline \multicolumn{7}{|c|}{ Patient or Population: Patients with Active I } \\
\hline \multicolumn{7}{|l|}{ Settings: Outpatients } \\
\hline \multicolumn{7}{|c|}{ Intervention: Enteric-coated Peppermint Oil Capsules vs. Placebo } \\
\hline \multirow[t]{3}{*}{ Outcomes } & \multicolumn{6}{|c|}{ Illustrative Comparative Risk* } \\
\hline & Assumed risk & Corresponding risk & & & & \\
\hline & $\begin{array}{l}\text { Control (per } \\
1000)\end{array}$ & $\begin{array}{l}\text { Peppermint Oil vs. Placebo (per } \\
\text { 1000) }\end{array}$ & $\begin{array}{l}\text { Relative Risk (95\% } \\
\text { Cl) }\end{array}$ & $\begin{array}{l}\text { No. Participants } \\
\text { (Studies) }\end{array}$ & $\begin{array}{l}\text { Quality of Evidence } \\
\text { (GRADE) }\end{array}$ & $\begin{array}{l}\text { NNT }(95 \% \\
\text { Cl) }\end{array}$ \\
\hline $\begin{array}{l}\text { Global improvement in IBS } \\
\text { symptoms }\end{array}$ & $250+$ & 598 (483 to 743 ) & $2.39(1.93-2.97)$ & $507(7)$ & $\oplus \oplus \oplus \oplus \neq$ High & $3(2-4)$ \\
\hline Improvement in abdominal pain & $303+$ & 539 (433 to 666) & $1.78(1.43-2.20)$ & $556(6)$ & $\oplus \oplus \oplus \circ \S$ Moderate & $4(3-6)$ \\
\hline Adverse events & $21+$ & 29 (18 to 47$)$ & $1.40(0.87-2.26)$ & $671(8)$ & $\oplus \oplus \circ)$ ll Low & $125(29-\infty$ \\
\hline \multicolumn{7}{|c|}{$\begin{array}{l}\text { GRADE Working Group grades of evidence. High quality: further research is very unlikely to change our confidence in the estimate of effect. Moderate quality: } \\
\text { further research is likely to have an important impact on our confidence in the estimate of effect and may change the estimate. Low quality: further research is } \\
\text { very likely to have an important impact on our confidence in the estimate of effect and is likely to change the estimate. Very low quality: we are very uncertain } \\
\text { about the estimate } \\
\text { *The basis for the assumed risk is the median control group risk across studies). The corresponding risk (and its } 95 \% \text { Cl) is based on the assumed risk in the } \\
\text { comparison group and the relative effect of the intervention (and its } 95 \% \mathrm{Cl}) \\
\text { †Control group risk estimates come from the control arm of meta-analysis, based on included trials } \\
\oplus \oplus \oplus \oplus \neq \text { High: downgraded on risk of bias, upgraded on large magnitude of effect } \\
\oplus \oplus \oplus \bigcirc \text { Moderate: downgraded on risk of bias } \\
\oplus \oplus \circ \text { II Low: downgraded on risk of bias and imprecision } \\
\text { Cl indicates confidence interval }\end{array}$} \\
\hline
\end{tabular}

criteria to define symptom improvement was heterogeneous and included pain and/or global symptom improvement [8]. We separately analyzed the ability of PO to improve abdominal pain and global IBS symptoms. A limited risk of bias showed that all studies lacked concealed allocation. It is worth mentioning that a meta-analysis was not conducted on the side-effect data as only three trials reported adverse events.

In 2011, Ruepert et al. published the results of their systematic review and meta-analysis on the effectiveness of antispasmodics, antidepressants, and bulking agents in IBS, which included the randomized controlled trials of PO versus placebo [17]. PO was shown to improve global symptoms; risk ratio was 2.25 [1.70-2.98] in two studies with 225 patients $[31,34]$. PO also improved the IBS symptom score vs. placebo; risk ratio was 1.94 [1.09-3.46] in three studies with 269 patients [30, 31, 42]. Their analysis of spasmolytics for the relief of abdominal pain demonstrated the superiority of $\mathrm{PO}$ versus placebo; risk ratio was 2.15 [1.54, 3.00] in one trial of 101 patients [35].

The most recent meta-analysis by Khanna et al. (2014) evaluated 726 patients [19] from nine [29, 30-32, 34-37, 43] included studies. Global IBS symptom improvement was reported to be greater for PO versus placebo ( 5 studies, 392 patients, relative risk 2.23; 95\% confidence interval, 1.78-2.81), and likewise for improvement in abdominal pain (5 studies, 357 patients, relative risk 2.14; 95\% confidence interval, 1.64-2.79). Khanna et al.'s pooled analysis of seven studies and 474 patients reported that IBS patients treated with PO, as compared to the placebo, were more likely to experience an adverse event, such as heartburn, which tended to be mild and transient [19].
In 2018 Ford et al. published a systematic review of RCTs using medical, psychological and nutritional therapies for IBS as an updated monograph for the American College of Gastroenterology [44]. The 2014 version included five RCTs of PO versus placebo for IBS [45]. The primary outcome of improved IBS outcome was not defined according to global symptoms versus pain relief. The search terms were merged for a number of interventions (i.e. fiber, diet) with colpermin and peppermint oil being utilized to identify RCTs using PO for IBS. Seven RCTs involving 634 patients were included and the pooled analysis showed benefit for PO over placebo (RR-0.54; 95\% CI 0.39-0.76). The number needed to treat in order for one patient to benefit was four but the endpoint of IBS improvement was not defined and heterogeneity was high $\left(I^{2}=73 \%, P=\right.$ 0.001). Pooled data on adverse events from six studies did not show a difference between PO and placebo. One of the two new included studies was a comparative study of peppermint oil and anise oil to placebo [46] with a visual analog scale and quality of life as primary and secondary endpoints. For these reasons, this study was excluded from our analysis.

Overall, we evaluated 835 adult patients from twelve studies that met the inclusion criteria. Improved global IBS symptomatology was greater for PO when compared to placebo, as well as for abdominal pain. We included studies excluded by Khanna et al. [20, 22, 33, 38] and excluded their included study on pediatric IBS [47]. Unlike Khanna et al., we did not detect a difference in the adverse events reported in IBS subjects using PO versus placebo. Our risk of bias analysis also differed from that of Khanna et al., as we found a high risk of bias for Cash et al. [22] for industry funding and attrition bias for Cappello et al. 
[30], Rees et al. [20], and Weiss et al. [37], which shall bring necessary caution to result interpretation. In our study, the number needed to treat with PO to prevent one patient from having persistent symptoms was three for global symptoms and four for abdominal pain.

\section{Conclusions}

Enteric-coated peppermint oil is a safe and effective therapy for the relief of abdominal pain and global symptoms and in adults with IBS.

\section{Additional files}

Additional file 1: Table of Medical Literature Search Results for Randomized Controlled Trials of Enteric-Coated Peppermint Oil for the Irritable Bowel Syndrome. We searched the medical literature for randomized controlled trials of enteric-coated peppermint oil for the treatment of the irritable bowel syndrome. Our search methodology yielded 102 reports in PubMed, 396 in Embase, 201 in Web of Science, and 60 in the Cochrane library. (PDF $265 \mathrm{~kb}$ )

Additional file 2: Table of Excluded Studies. Ten of twenty-two included randomized controlled trials (RCTs) were eliminated for reasons shown. Five studies for data that was shown in other publications, four RCTs were cross-over trials without sufficient washout period, and an RCT was permitted rescue medication without sufficient data to permit analysis. (PDF $369 \mathrm{~kb})$

\section{Abbreviations}

Cl: Confidence interval; EPO: Enteric-coated peppermint oil; FODMAPs: Fermentable oligo-, di-, and monosaccharides and polyols; IBS: Irritable bowel syndrome; IBS-C: Irritable bowel syndrome: constipation predominant; IBS-D: Irritable bowel syndrome: diarrhea predominant; IBSM: Irritable bowel syndrome: mixed; IBS-U: Irritable bowel syndrome: undetermined; NNT: Number needed to treat; PO: Peppermint oil; RCTs: Randomized clinical trials; RR: Risk ratio; TISS: Total IBS symptom score

\section{Acknowledgments}

Not applicable.

\section{Funding}

Not applicable.

\section{Availability of data and materials}

The datasets used and/or analyzed during the current study are available from the corresponding author on reasonable request.

\section{Authors' contributions}

$\mathrm{NA}, \mathrm{BS}, \mathrm{GEM}$ contributed to the data evaluation, manuscript and figure preparation, editing, and final submission. RTS and LW provided the biostatistics methodology oversight, data extractions, meta-analysis with pooled data, figure preparation, and manuscript preparation, and editing. GH provided the data extraction and a critical review of the manuscript and editorial guidance. JN provided the informatics methodology support, conducted the literature search, and reviewed and edited the manuscript. All authors have approved the final version of the manuscript.

Ethics approval and consent to participate

Not applicable.

\section{Consent for publication}

Not applicable.

\section{Competing interests}

Dr. Mullin is an Associate Editor of BMC Complementary and Alternative Medicine.

\section{Publisher's Note}

Springer Nature remains neutral with regard to jurisdictional claims in published maps and institutional affiliations.

\section{Author details}

${ }^{1}$ The Division of Gastroenterology and Hepatology, The Johns Hopkins University School of Medicine, 600 N. Wolfe Street, Baltimore, MD 21287, USA. ${ }^{2}$ King Khalid University Hospital, King Saud University, P.O. Box 2925, Riyadh 11461, Saudi Arabia. ${ }^{3}$ The Johns Hopkins School of Public Health, Baltimore, MD, USA. ${ }^{4}$ The Division of Liver Medicine, Gastroenterology, The Mount Sinai Hospital, New York, NY, USA. ${ }^{5}$ Department of Gastroenterology \& Hepatology, Princess Alexandra Hospital, Brisbane, University of Queensland, QLD, Brisbane, Australia. ${ }^{6}$ Department of Biostatistics, Epidemiology, \& Informatics, Perelman School of Medicine, University of Pennsylvania, Philadelphia, PA, USA.

Received: 3 August 2018 Accepted: 13 December 2018

Published online: 17 January 2019

\section{References}

1. Schmulson MJ, Drossman DA. What is new in Rome IV. J Neurogastroenterol Motil. 2017;23(2):151-63.

2. Choung RS, Locke GR 3rd. Epidemiology of IBS. Gastroenterol Clin N Am. 2011:40(1):1-10.

3. Lovell RM, Ford AC. Global prevalence of and risk factors for irritable bowel syndrome: a meta-analysis. Clin Gastroenterol Hepatol. 2012;10(7):712-21.e4.

4. Buono JL, Carson RT, Flores NM. Health-related quality of life, work productivity, and indirect costs among patients with irritable bowel syndrome with diarrhea. Health Qual Life Outcomes. 2017;15(1):35.

5. Oswiecimska J, Szymlak A, Roczniak W, Girczys-Poledniok K, Kwiecien J. New insights into the pathogenesis and treatment of irritable bowel syndrome. Adv Med Sci. 2017;62(1):17-30.

6. Singh R, Salem A, Nanavati J, Mullin GE. The role of diet in the treatment of irritable bowel syndrome: a systematic review. Gastroenterol Clin N Am. 2018:47(1):107-37.

7. Mullin GE, Shepherd SJ, Chander Roland B, Ireton-Jones C, Matarese LE. Irritable bowel syndrome: contemporary nutrition management strategies. JPEN J Parenter Enteral Nutr. 2014;38(7):781-99.

8. Ford AC, Talley NJ, Spiegel BM, Foxx-Orenstein AE, Schiller L, Quigley EM, et al. Effect of fibre, antispasmodics, and peppermint oil in the treatment of irritable bowel syndrome: systematic review and meta-analysis. BMJ. 2008; 337:a2313.

9. Hawthorn M, Ferrante J, Luchowski E, Rutledge A, Wei XY, Triggle DJ. The actions of peppermint oil and menthol on calcium channel dependent processes in intestinal, neuronal and cardiac preparations. Aliment Pharmacol Ther. 1988;2(2):101-18.

10. de Sousa Guedes JP, da Costa Medeiros JA, de Souza ESRS, de Sousa JM, da Conceicao ML, de Souza EL. The efficacy of Mentha arvensis L. and M. piperita L. essential oils in reducing pathogenic bacteria and maintaining quality characteristics in cashew, guava, mango, and pineapple juices. Int J Food Microbiol. 2016;238:183-92.

11. McKay DL, Blumberg JB. A review of the bioactivity and potential health benefits of peppermint tea (Mentha piperita L.). Phytother Res. 2006;20(8): 619-33.

12. Grigoleit HG, Grigoleit P. Gastrointestinal clinical pharmacology of peppermint oil. Phytomedicine. 2005;12(8):607-11.

13. Ford AC. Effect of fibre, antispasmodics, and peppermint oil in the treatment of irritable bowel syndrome: systematic review and meta-analysis (vol 337, a2313, 2008). Br Med J. 2009;338.

14. Pittler MH, Ernst E. Peppermint oil for irritable bowel syndrome: a critical review and metaanalysis. Am J Gastroenterol. 1998;93(7):1131-5.

15. Huertas-Ceballos A, Logan S, Bennett C, Macarthur C. Pharmacological interventions for recurrent abdominal pain (RAP) and irritable bowel syndrome (IBS) in childhood. Cochrane Database Syst Rev. 2008;(1): CD003017. https://doi.org/10.1002/14651858.CD003017.pub2.

16. Mann N, Sandhu K. Peppermint oil in irritable bowel syndrome: evaluation of 1634 cases with qualitative meta-analysis. Am J Gastroenterol. 2010;105:S481-\$2.

17. Ruepert L, Quartero AO, de Wit NJ, van der Heijden GJ, Rubin G, Muris JW. Bulking agents, antispasmodics and antidepressants for the treatment of irritable bowel syndrome. Cochrane Database Syst Rev. 2011;(8):Cd003460. 
18. Mann NS, Sandhu KS. Peppermint oil in irritable bowel syndrome: systematic evaluation of 1634 cases with meta-analysis. Int Med J. 2012;19(1):5-6.

19. Khanna R, MacDonald JK, Levesque BG. Peppermint oil for the treatment of irritable bowel syndrome: a systematic review and meta-analysis. J Clin Gastroenterol. 2014;48(6):505-12.

20. Rees WD, Evans BK, Rhodes J. Treating irritable bowel syndrome with peppermint oil. Br Med J. 1979;2(6194):835-6.

21. Lesbros-Pantoflickova D, Michetti P, Fried M, Beglinger C, Blum AL. Metaanalysis: the treatment of irritable bowel syndrome. Aliment Pharmacol Ther. 2004;20(11-12):1253-69.

22. Cash BD, Epstein MS, Shah SM. A novel delivery system of peppermint oil is an effective therapy for irritable bowel syndrome symptoms. Dig Dis Sci. 2016;61(2):560-71.

23. Liberati A, Altman DG, Tetzlaff J, Mulrow C, Gotzsche PC, loannidis JP, et al The PRISMA statement for reporting systematic reviews and meta-analyses of studies that evaluate health care interventions: explanation and elaboration. PLoS Med. 2009;6(7):e1000100.

24. Sayers A. Tips and tricks in performing a systematic review. Br J Gen Pract. 2007:57(538):425.

25. Higgins JP, Altman DG, Gotzsche PC, Juni P, Moher D, Oxman AD, et al. The Cochrane Collaboration's tool for assessing risk of bias in randomised trials. BMJ. 2011;343:d5928.

26. Balshem $H$, Helfand M, Schunemann HJ, Oxman AD, Kunz R, Brozek J, et al. GRADE guidelines: 3. Rating the quality of evidence. J Clin Epidemiol. 2011; 64(4):401-6.

27. Higgins JPT. Cochrane Handbook for Systematic Reviews of Interventions. Version 510 The Cochrane Collaboration 2016

28. Egger M, Smith GD, Phillips AN. Meta-analysis: principles and procedures. BMJ. 1997;315(7121):1533-7.

29. Alam MS, Roy PK, Miah AR, Mollick SH, Khan MR, Mahmud MC, et al. Efficacy of peppermint oil in diarrhea predominant IBS - a double blind randomized placebo - controlled study. Mymensingh medical journal : MMJ. 2013;22(1):27-30

30. Cappello G, Spezzaferro M, Grossi L, Manzoli L, Marzio L. Peppermint oil (Mintoil((R))) in the treatment of irritable bowel syndrome: a prospective double blind placebo-controlled randomized trial. Dig Liver Dis. 2007;39(6):530-6.

31. Capanni M, Surrenti E, Biagini MR, Milani S, Surrenh C, Galli A. Efficacy of peppermint oil in the treatment of irritable bowel syndrome: a randomized, controlled trial. Gazz med ital arch sci med [Internet]. 2005; 164(2):119-26.

32. Merat S, Khalili S, Mostajabi P, Ghorbani A, Ansari R, Malekzadeh R. The effect of enteric-coated, delayed-release peppermint oil on irritable bowel syndrome. Dig Dis Sci. 2010;55(5):1385-90.

33. Dew MJ, Evans BK, Rhodes J. Peppermint Oil for the Irritable Bowel Syndrome - a Multicenter Trial. Br J Clin Pract. 1984;38(11-1):394.

34. Lech Y, Olesen KM, Hey H, Rask-Pedersen E, Vilien M, Ostergaard O. Treatment of irritable bowel syndrome with peppermint oil. A double-blind investigation with a placebo. Ugeskr Laeger. 1988;150(40):2388-9.

35. Liu JH, Chen GH, Yeh HZ, Huang CK, Poon SK. Enteric-coated peppermint-oil capsules in the treatment of irritable bowel syndrome: a prospective, randomized trial. J Gastroenterol. 1997;32(6):765-8.

36. Schneider MMEOM. Efficacy of Colpermin in the treatment of patients with irritable bowel syndrome. Gastroenterology. 1990;98.

37. Weiss WKC. Treatment of irritable bowel syndromewith peppermint oil capsules: results of a double blind study. Therapiewoche Osterreich. 1988;3:3-8.

38. Carling L, Svedberg LE, Hulten S. Short term treatment of the irritable bowel syndrome: a placebo-controlled trial of peppermint oil against hyoscyamine. Opuscula Medica. 1989;34(3):55-7.

39. Sterne JA, Sutton AJ, loannidis JP, Terrin N, Jones DR, Lau J, et al. Recommendations for examining and interpreting funnel plot asymmetry in meta-analyses of randomised controlled trials. BMJ. 2011;343:d4002.

40. Nash P, Gould SR, Bernardo DE. Peppermint oil does not relieve the pain of irritable bowel syndrome. Br J Clin Pract. 1986:40(7):292-3.

41. Jadad AR, Moore RA, Carroll D, Jenkinson C, Reynolds DJ, Gavaghan DJ, et al. Assessing the quality of reports of randomized clinical trials: is blinding necessary? Control Clin Trials. 1996;17(1):1-12.

42. Czalbert HJNM, Feher K. Experiences with colpermintherapy (Tillots-England) at patients of irritable colon syndrome. Gyogyszereszet. 1990;34(5):251-3.

43. Kline RM, Kline JJ, Di Palma J, Barbero GJ. Enteric-coated, pHdependent peppermint oil capsules for the treatment of irritable bowel syndrome in children. J Pediatr. 2001;138(1):125-8.
44. Ford AC, Moayyedi P, Chey WD, Harris LA, Lacy BE, Saito YA, et al. American College of Gastroenterology monograph on management of irritable bowel syndrome. Am J Gastroenterol. 2018;113(Suppl 2):1-18.

45. Ford AC, Moayyedi P, Lacy BE, Lembo AJ, Saito YA, Schiller LR, et al. American College of Gastroenterology monograph on the management of irritable bowel syndrome and chronic idiopathic constipation. Am J Gastroenterol. 2014;109( Suppl 1):S2-26; quiz S7.

46. Mosaffa-Jahromi M, Lankarani KB, Pasalar M, Afsharypuor S, Tamaddon AM. Efficacy and safety of enteric coated capsules of anise oil to treat irritable bowel syndrome. J Ethnopharmacol. 2016;194:937-46.

47. Klein KB. Treatment of the irritable bowel syndrome. Drugs of Today. 1988; 24(8):589-95.
Ready to submit your research? Choose BMC and benefit from:

- fast, convenient online submission

- thorough peer review by experienced researchers in your field

- rapid publication on acceptance

- support for research data, including large and complex data types

- gold Open Access which fosters wider collaboration and increased citations

- maximum visibility for your research: over $100 \mathrm{M}$ website views per year

At BMC, research is always in progress.

Learn more biomedcentral.com/submissions 